\title{
Using Latent Profile Analysis for a Unique Perspective of a University Transfer Student Cohort
}

\author{
Tracey N. Sulak, Jennifer Massy, and David Thomson
}

Transfer students differ from traditional first-year students on a number of variables that are typically related to retention and academic success at four-year institutions. While data-driven policies and programming represent a powerful method for meeting the needs of students, applying theories developed on traditional first-year students in order to understand transfer student performance may not reveal the unique needs in the transfer subpopulation. Latent profile analysis (LPA) offers a method for understanding performance in a diverse population while still honoring the characteristics of the individuals through person-centered analysis. In the current study, LPA was used to classify a diverse cohort of transfer students $(n=417)$ into subclasses based on similar variable distributions and response patterns. Implications for practice according to the composition of class are discussed.

\section{Introduction}

Students who transfer into a four-year institution represent a unique subpopulation in higher education. Nationally, about a quarter of college students transfer from their primary institution before graduation, and within that $25 \%$, students from a higher SES are five times more likely to transfer when compared to students from the lowest SES quartile (Dougherty, \& Kienzl, 2006). The sixyear graduation rate for low-income students is $54 \%$, which lags far behind the high-income students' six-year rate of $77 \%$, and in addition, transfer students who are also low income are among the least likely to persist to graduation (Melguizo \& Dowd, 2009; Rendón, Jalomo, \& Nora, 2000). Retention of transfer students over the course of their first year at a new institution represents a challenge for the students and a challenge to the universities.

Unfortunately, the research in this area is lacking when compared to the research conducted on the typical first-year student. In addition, the research that was conducted often compares transfer students to first-year students in an

Tracey N. Sulak (Tracey_Sulak@Baylor.edu), Department of Educational Psychology at Baylor University Jennifer Massey is the Assistant Dean for Student Learning \& Engagement at Baylor University

David Thomson, Department of Educational Psychology at Baylor University 
effort to identify differences and similarities between the two groups (Adelman, 2005; Cabrera, Burkum, \& La Nasa, 2005). These findings have been used to formulate interventions designed to meet the needs of both groups, but in doing so, the considerable variability found in both groups of students is ignored (Townsend \& Wilson, 2006). While it is possible some interventions may meet the needs of some first-year and some transfer students, we argue that the transfer subpopulation on a four-year campus brings a unique set of needs and as such, deserves a research agenda designed to provide information for meeting these unique needs. Latent profile analysis, or LPA helps researchers to find subgroups within a diverse population, and it has been previously applied in the study of college student achievement goal orientations, but has not been used in the study of retention of transfer students (Pastor, Barron, Miller, \& Davis, 2007).

\section{Literature Review}

Transfer students face unique challenges when entering a four-year institution, such as navigating a new enrollment system, understanding new academic standards, finding classes and resources on a new campus, and integrating into the social fabric of a university (Townsend \& Wilson, 2006; Dougherty, \& Kienzl, 2006; Lee, Mackie-Lewis, \& Marks, 1993). For example, in one longitudinal study of transfer students, Porchea, Allen, Robbins, and Phelps (2010) found that nearly half of the 4,481 students included in the study had not earned a community college degree or certificate, did not transfer to a four-year college, or were no longer enrolled in post-secondary education at the end of five years. In this study, academic preparation, parental income, and parental education appeared to be the best predictors of transferring to a four-year college. Over the course of 5 years, students were more likely to obtain a degree if they were enrolled fulltime, had higher degree expectations, and worked fewer hours (Porchea et al., 2010). New student programs and extended orientations often fill this role for typical first-year students, and while many universities are now designing these programs for transfer students, the challenge is meeting the needs of the transfers without treating the group like they are first-year students (Caplan, 2008; Herman \& Lewis, 2004). It has also been suggested that while many transfer students may be academically prepared for the four-year institution, they may not be psychologically or emotionally prepared for the changes encountered during transition (Ward-Roof, Kashner, \& Hodge, 2003; Melguizo, Kienzl, \& Alfonso, 2011). In spite of this knowledge, traditional research has not been able to identify which students a particular intervention will best serve and as such, most firstyear programs, even those that include transfer students, are focused on fostering involvement, creating friendships, and proliferating university traditions (Bai \& Pan, 2009).

Unfortunately, research on retention and success of transfer students has borrowed from similar research on traditional students. The theories applied to traditional first-year students, such as Tinto's (1975) model of student retention, may not be as effective at explaining transfer student behaviors because these 
models were created from and normed on a different student population (Pascarella \& Terenzini, 1997). When these models are applied to transfer behavior, the results may be more statistical noise than actual findings and lead administrators to create well-intentioned programs that are not designed to meet the needs of the transfer college student. Traditional retention analysis, such as linear regression, represents a variable-oriented approach, which means the goal of the analysis is to reveal relationships among the analyzed variables (Collins \& Lanza, 2010). This type of analysis works well when the goal is determining which variables contribute the most to retention at a university or in a program, but when the goal is creating an intervention, then the analysis needs to show patterns of characteristics or responses that have a higher probability of retention. Latent profile analysis uses the response patterns of individuals, or characteristics, and creates clusters of similar patterns. This is referred to as a person-oriented approach, and it can be used to organize a highly variable dataset into more manageable, homogenous classes (Collins \& Lanza, 2010).

While traditional retention analysis indicates the characteristics and demographics related to transferring to a four-year institution resemble the same characteristics related to academic success in traditional college populations (Pascarella \& Terenzini, 1997), person-oriented approaches like latent profile analysis may reveal patterns that are not visible with variable-oriented approaches. According to prior research, transfer students may engender greater variability when compared to traditional first-year students because of racial and ethnic disparities in the use of the transfer function as a route to a four-year degree (Townsend, 1995; Zamani, 2001). When using parametric statistics, like regression and analysis of variance, the variability may obscure relationships between variables, but latent profile analysis can harness the natural variability to show the prevalence of a particular subgroup and the relationship between that subgroup and retention (Collins \& Lanza, 2010). This study will use latent profile analysis to study the entering 2010 cohort of transfer students at a private, research-intensive university. A description of latent profile analysis will be included in the analysis section. Specific research questions will be addressed as follows:

1. Are there distinct subgroups of transfer students that engage in particular kinds of academic behaviors?

2. What is the prevalence of these profiles in a typical transfer cohort at a mid-sized, research-intensive university?

3. How are these profiles related to short- and long-term retention at the new institution?

\section{Method}

\section{Setting}

The study took place at a mid-sized, private, southern, faith-based, selective, research-intensive university. The undergraduate population is approximately 14,000 students with a graduate population of approximately 2,000 students. 
The percentage of transfer students at the university is approximately $13 \%$ of the undergraduate students. The data utilized in the study was housed in the student record system and was collected on all students at entry to the university.

\section{Participants}

The current study utilized entering transfer students $(n=417)$. The sample was approximately $39 \%$ male $(n=161)$ and $61 \%$ female $(n=256)$. Concerning ethnicity and race, approximately $65 \%(n=271)$ identified as Caucasian or White, $19 \%(n=80)$ identified as Hispanic, 4\% $(n=15)$ identified as Asian, 9\% $(n=36)$ identified as Black or African American, and 4\% $(n=15)$ identified as Multiracial. Approximately 93\% ( $n=389)$ were retained for the spring semester of the first year of their transfer experience, and $78 \%(n=324)$ were retained to the fall of the second year at their new institution.

\section{Measures}

All data used in the current study were collected as part of the institutional data process. The university routinely collects information related to demographics, status, and academic performance on all enrolled students. Minority status, gender, SES, deficiencies, referrals, probation, retention, first-generation status, and grade point average (GPA) were used in the current study. For the purposes of this study, students were identified as low SES based on values used on the Free Application for Federal Student Aid. Incomes in the lowest quartile were classified as low SES. Minority status was assigned if a student was not Caucasian. Deficiencies are filed on students who have earned below a 2.0 at mid-semester and referrals are filed at any time during the semester for low grades, excessive absences, behavioral indicators in class, a lack of response to an instructor's concerns, or any other indicator the student may be in jeopardy of academic failure. Probation occurs when the GPA is below a 2.0 at the end of a semester. After initial analyses, major of study was used as a way to understand the results.

\section{Analysis}

Descriptive information pertaining to the eight variables used to conduct the latent profile analysis may be found in Table 1 . All analyses were conducted in SPSS (v.20) or Mplus (v.6.12). Latent profile analysis (LPA) was used to find latent, or hidden, subgroups within the transfer population of the 2010 entering cohort using the following variables: sex, fall deficiencies, spring deficiencies, fall grade point average, spring grade point average, socioeconomic status as a dichotomy, first-generation status, and minority status. LPA uses the response patterns available in the data to derive an array of latent classes from specified indicator variables (Muthén \& Muthén, 2000). Approaches like LPA are considered personcentered because the analysis uses the patterns of behavior expressed by individuals 
TABLE 1

\title{
Descriptive Statistics for the Variables used in the Latent Class Analysis
}

Means (SD) $\quad$ Frequency

\author{
Fall GPA \\ Spring GPA \\ Fall Deficiencies \\ Spring Deficiencies \\ First Generation Status \\ Low SES Status \\ Minority Status
}

$2.65(0.98)$

$2.52(1.15)$

$\begin{array}{ll}\text { No }-74.8 \% & \text { Yes }-25.2 \% \\ \text { No }-80.8 \% & \text { Yes }-19.2 \% \\ \text { No }-83.2 \% & \text { Yes }-16.8 \% \\ \text { No }-83.7 \% & \text { Yes }-16.3 \% \\ \text { No }-54.4 \% & \text { Yes }-45.6 \%\end{array}$

Note: All statistics are based on $n=417$.

to extract profiles, which can then be linked to broader theoretical phenomena. For the current study, LPA presents a viable alternative to other analytical procedures, since it can use categorical or continuous indicator items.

LPA uses the response patterns found in the data to estimate two sets of parameters: latent class prevalences and item-response probabilities (Collins \& Lanza, 2010). Latent class prevalences represent the probability of belonging to a specific, exclusive class and are calculated using the item-response probabilities (Collins \& Lanza, 2010). Individuals receive a probability indicating the likelihood of belonging to each latent class, which seems to negate the classes being mutually exclusive; however, the model is estimating an unmeasured or latent class based on item-response patterns rather than the responses of a single individual. This makes it possible for individuals to have a probability of classification in all classes, even as the classes are mutually exclusive.

The item-response probabilities provide the qualitative descriptors used to describe each class because they are associated with the observed responses most likely associated with a specific class (Muthén \& Muthén, 2010). In this study, the qualitative descriptors include sex, fall deficiencies, spring deficiencies, socioeconomic status as a dichotomy, first-generation status, and minority status. These items provide descriptive information about the individuals included in each class based on the item-response probabilities or the probability of an individual with a specific characteristic, such as low SES, being assigned to a certain class. Item-response probabilities, like latent class prevalences, range between 0 and 1, with all the probabilities summing to 1 across a variable. For example, in a hypothetical 3-class model, the item-response probabilities for being female may be .20 for Class 1, .70 for Class 2, and .10 for Class 3. The probabilities sum to 1 , but the item-response probabilities also indicate a high likelihood females 
will be classified in Class 2. When classes exhibit a high degree of homogeneity, such that all individuals within each class manifest the same response pattern, then the latent classes have a simple structure, and all classes should have a high degree of separation (Collins \& Lanza, 2010). In reality, a simple structure may be difficult to achieve, and like cross-loadings in factor analysis, individuals will display a response pattern that could be classified in more than one latent class, resulting in the need to observe posterior probabilities of latent class membership. These probabilities refer to the probability of membership in a class based on the displayed response pattern (Collins \& Lanza, 2010).

The process for model development begins with a single class solution, and classes are added per iteration until the model no longer fits the data. Models are designed to fit the data, but making the decision about which model fits the data best presents a challenge. In the case of LPA, multiple fit indicators can help the research make the best decision. Evaluating the posterior probabilities, itemresponse probabilities, and latent class prevalences can reveal the utility of the model, and when these estimated values are used in conjunction with the entropy value, the model's classification utility can be determined (Collins \& Lanza, 2010). Entropy is a measurement of the separation between classes, but this value needs to be supported by other fit indicators, like Akaike and Bayesian information criteria, the chi-square values, and the Parametric Bootstrapped Likelihood Ratio Test (Collins \& Lanza, 2010). The Akaike information criterion and the Bayesian information criterion offer indication of fit, while also adjusting for parsimony, while chi-square tests only test fit with no adjustment (Collins \& Lanza, 2010). To support the fit indicators, we used the Parametric Bootstrapped Likelihood Ratio Test to help in model selection. This test provides additional support for a $k$-class versus a $k-1$ class solution (Muthén \& Muthén, 2010). By evaluating the solution holistically through these different fit indicators, the number of classes that best

TABLE 2

\section{Fit Statistics for Latent Class Analysis of Transfer Behavior}

\begin{tabular}{|c|c|c|c|c|c|c|}
\hline $\begin{array}{l}\text { Number } \\
\text { of Latent } \\
\text { Classes }\end{array}$ & $\begin{array}{l}\text { Number } \\
\text { of } \\
\text { Parameters } \\
\text { Estimated }\end{array}$ & 2 & $d f$ & AIC & BIC & $l$ \\
\hline 1 & 11 & $44.0 * *$ & 26 & 5229.3 & 5273.6 & -2603.6 \\
\hline 2 & 20 & $43.6^{*}$ & 20 & 5016.7 & 5097.4 & -2488.4 \\
\hline 3 & 29 & $28.1^{* *}$ & 14 & 4856.2 & 4973.2 & -2399.1 \\
\hline 4 & 38 & $24.8^{* *}$ & 8 & 4783.1 & 4936.3 & -2353.5 \\
\hline 5 & 47 & $20.9 * * *$ & 2 & 4818.6 & 5008.1 & -2362.3 \\
\hline
\end{tabular}




\section{Four-Class Model of Transfer Students $(n=417)$}

\section{Latent Class}

$\begin{array}{llll}\begin{array}{l}\text { Students From } \\ \text { Low SES with }\end{array} & \text { Majority } & \text { Female Students } & \text { Female Majority } \\ \text { low academic } & \text { Low SES } & \text { with Possible } & \text { Students not From } \\ \text { achievement } & & \text { Low SES } & \text { Low SES }\end{array}$

Latent class

.09

.05

.40

.45

prevalences

Item-response

probabilities

Gender

$\begin{array}{lrrrr}\text { Male } & .46 & .45 & .37 & .38 \\ \text { Female } & .54 & .55 & .63 & .62\end{array}$

Low SES

$\begin{array}{rrrrr}\text { Yes } & .28 & .23 & .20 & .09 \\ \text { No } & .72 & .77 & .80 & .91\end{array}$

Minority

$\begin{array}{lrrrr}\text { Yes } & .56 & .64 & .58 & .66 \\ \text { No } & .44 & .36 & .42 & .34\end{array}$

First Generation

Status

$\begin{array}{rrrrr}\text { Yes } & .44 & .00 & .19 & .11 \\ \text { No } & .56 & 1.0 & .81 & .89\end{array}$

Fall Deficiency

$\begin{array}{rrrrr}\text { Yes } & .22 & .14 & .58 & .12 \\ \text { No } & .78 & .85 & .42 & .88\end{array}$

Spring Deficiency

$\begin{array}{lrrrr}\text { Yes } & .18 & .00 & .38 & .05 \\ \text { No } & .82 & 1.0 & .62 & .95\end{array}$

Means and

Standard

Deviations

$\begin{array}{lllll}\text { Fall GPA } & 0.87 & 3.03 & 2.18 & 3.40 \\ \text { Spring GPA } & 0.39 & 0.08 & 2.38 & 3.36\end{array}$

Note: $\quad$ Fall and spring deficiencies are reported by faculty in the 8th week of each semester. Reasons for reporting deficiencies include excessive absences, missing assignments, low test or assignment scores, and coming to class unprepared. 
fits the data can be determined. The classes derived through the LPA can then be compared through frequencies and chi square tests to determine if the classes differed on institutional variables linked to retention.

\section{Results}

Descriptive statistics for the variables included in the LPA may be found in Table 1, and the fit statistics associated with the LPA may be found in Table 2. The fit statistics support a 4-class solution, and this was also supported by the results of the Parametric Bootstrapped Likelihood Ratio Test, but not by the results of the Vuogn-Lo-Mendell-Rubin Likelihood Ratio Test. Since the preponderance of evidence suggests the 4-class solution is the best fit of the model to the data, all reported results will be based on that solution. As seen in Table 2, the AIC and BIC values decrease from a 2-class solution to a 4-class solution, but when a 5-class solution is estimated, the value increases, which indicates the 5-class solution does not balance parsimony with model fit as well as the 4-class solution. In addition, the relatively high entropy value for the 4-class solution indicates the 4-classes represent a simple structure with the lowest amount of overlap or cross-classification when compared to the other solutions. Figure 1 illustrates the prevalence of classes based on a 4-class solution, which also illustrates the differences among the GPA in the classes from the 4-class solution but also shows the consistency of GPA within each class over the course of two semesters. The entropy value of .85 for the 4-class solution suggests a probability for membership in more than one latent class for some response patterns, specifically the patterns associated with Class 3 and Class 4 . Item-response probabilities associated with the 4-class solution may be found in Table 3 . In addition, the GPAs differed among the four classes, and this information is included in Table 3 and shown in Figure 1.

The classes also differed by variables not included in the LPA. Class 1 and 3 were more likely to receive academic probation in the fall: $\chi^{2}(3)=136.95, p<.001$. Class 3 was also associated with more academic probations in the spring: $\chi^{2}(3)=$ $72.93, p<.001$. Students in Class 1 were 7.7 standard deviations more likely to leave the university after the first fall semester, but students in Class 3 all retained to the spring semester, which may provide some explanation for the lack of spring academic probation within Class 1 . Class 2, like Class 1, was associated with increased attrition for the spring semester: $\chi^{2}(3)=184.73, p<.001$. The same pattern occurs with retention for the following fall: $\chi^{2}(3)=106.11, p<.001$.

\section{Discussion}

The results of the current study indicate the transfer cohort examined at this university was heterogeneous with respect to academic performance, demographic variables, and socioeconomic status. The LPA derived four distinct classes, which may mean the heterogeneity within the transfer cohort is actually created by four 


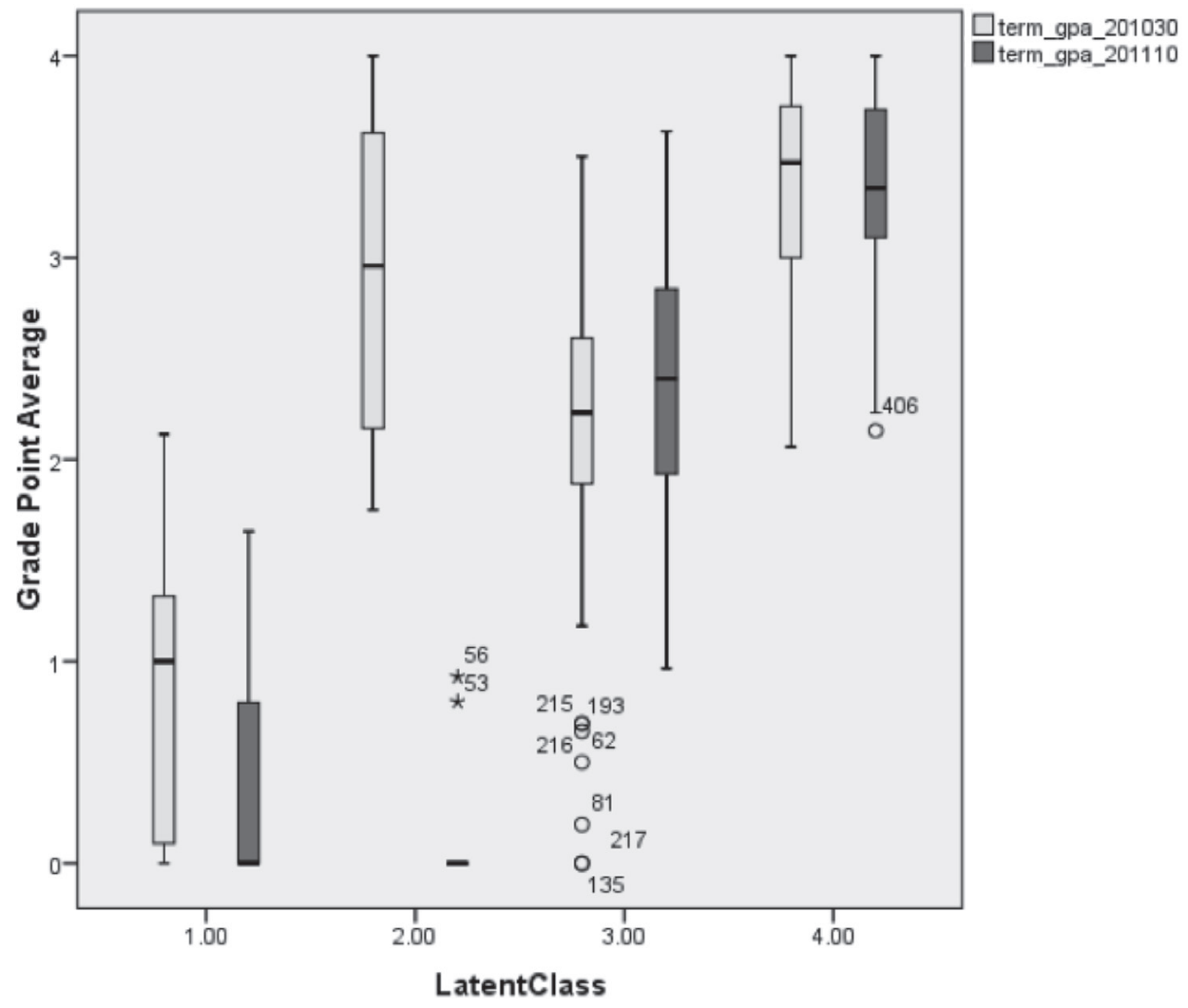

separate distributions with individual means and standard deviations. Prior research has suggested students transfer to four-year institutions for a variety of reasons, including programming available, residential experiences, friendships at the four-year school, or career goals (Townsend, 2008). The results of the current study appear to support the diversity found among cohorts of transfer students.

For the two smallest classes found in the LPA, some defining characteristics included higher financial concerns and attrition to spring of first year. Students in Class 1 performed poorly in the fall semester, and 39\% did not retain to the spring semester of the first year. This class was further differentiated by poor academic performance with average GPAs under 1.0 in majors like biology and engineering. Other research has suggested these fields may tend to draw a specific type of student or may foster a specific type of teaching that may not be effective with all students (Laird, Shoup, \& Kuh, 2005). The transfer students drawn to these majors 
may also experience greater "transfer shock," or the significant drop in grades after transfer to a four-year institution, when compared with students in other majors (Cejda, Kaylor, \& Rewey, 1998; Glass \& Harrington, 2002). Ironically, Glass and Harrington (2002) found the transfer shock to be the greatest for the lowest achieving students, like the students in Class 1 .

As an entering transfer student within a larger cohort, it may be difficult to recognize a student who may fit the profile of Class 1 . The demographic variables were evenly distributed among this class, but predominant majors and academic performance may help administrators identify transfer students who are in danger of not retaining past the first semester at a four-year institution. The early academic warning system at the university featured in this study did not identify all of the students who were at risk of failure in this class, but past research has suggested students who receive probation exhibit classes of behaviors that may be recognizable to faculty and staff, including a lower motivation, poor time management, poor study skills, higher external locus of control, and less defined academic and professional goals when compared with the average college student (Abelman \& Molina, 2001; Thombs, 1995; Tinto, 1993; Gordon \& Steele, 2003). Transfer students declaring biology and engineering majors who show these behavioral indicators may be at increased risk for attrition and may require additional services beyond early academic warning systems. In addition, students showing these behavioral indicators may be at greater risk for experiencing transfer shock, and given the majors of choice, this group of students may be least likely to recover from a dip in GPA.

Class 2, like Class 1, is comprised of transfer students who do not retain for the spring of the first year. This class, however, performs very well academically in the fall semester. Identification of this small class of students presents a challenge because the students do not exhibit the usual signs related to attrition. Class 2 also represents a number of different majors, including education, business, biology, and social sciences. Because these students do not retain past the first semester at the institution, they may represent unsuccessful integration into the fabric of the university as described by Tinto (1987). The theory suggests students enter with a level of institutional commitment that is then translated into separation, the second stage of departure. Since the students in this study are transfer students, they may enter the university with a lower level of institutional commitment, which then translates into a lower level of separation from prior institutions or friends than is experienced by other groups of students. When students negotiate separation from the past community successfully, they are more likely to retain (Tinto, 1987). Townsend and Wilson (2006) suggested transfer students may struggle to integrate because the new university provides an awkward fit when compared to the past institution, and the responsibility to adjust this fit may lie with the receiving institution rather than the individual transfer student.

Class 3 represents female students with moderate achievement who retained for the first year after transferring to the university. While the GPA for this class is above a 2.0, students in Class 3 received a greater number of fall and spring academic probations, which may indicate challenges with the academic systems in 
the university setting. Students in this class are mostly business and pre business majors, and the just-above-passing GPAs achieved over the course of two semesters may indicate the students are not adjusting completely to the academic rigor of these programs. This finding could also relate to a number of other issues, such as social integration, greater work hours due to SES status, or other elements related to academic validation (Elkins, Braxton, \& James, 2000). The students in Class 3 retained to the fall of the second year, which may be indicative of positive adjustment to the university. This is further supported by the increased GPA from fall to spring of the first year at the university. Non-transfer first-year students at the featured university often show the opposite pattern of GPA, with significant drops from fall to spring, but this drop does not appear to be related to retention among the traditional first-year students. Class 3 demonstrates a different pattern and may provide some evidence of how transfer students and traditional first-year students differ in performance patterns in relation to retention.

Class 4 represents the majority of transfer students in the current study. Students in this group are largely ethnic minority females and have high levels of academic achievement. Very few of the students received any form of early academic warnings, which suggests this class adapted quickly to the university setting. Approximately $25 \%$ of Class 4 declared a major of business or pre business, similar to Class 3, but the performance level differentiates the two groups of students. The positive adjustment of Class 4 identifies this group as potential source of data related to successful transition for transfer students, and given that this is the largest group of transfer students in the current study, it supports that the majority of transfer students do transition adequately over the course of the first year. While identifying students in Class 4 preemptively may be challenging, given the lack of academic warnings or other indicators, it appears this group does not need additional services to find academic success.

\section{Implications for Practice}

The current study has a number of implications for practice in higher education. First, it demonstrates the cohort of transfer students at the university studied was actually represented by four separate distributions. Each of these distributions contained a different mean and standard deviation with respect to GPA, a variable often used to represent academic achievement. These four distributions also behaved differently with respect to demographic categorical variables. Since all of the variables used in this study are routinely collected by offices of institutional research, the findings of this study could be replicated at any institution. Although the resulting distributions may be different given the characteristics of the college or university, the implications will be the same. Transfer cohorts are not a homogenous subset of students and should be served through interventions created to meet the specific needs of each subgroup.

For example, Class 1 represented struggling university students that retained for the first year, but not the second. Students in this class could benefit from additional support beyond the early academic warning system. When an early 
academic warning system is triggered for a low-achieving transfer student majoring in business, pre business, or biology, the student could be flagged for additional interventions by the student support center. In addition, students in Class 1 are ideal candidates for a first-year seminar. The seminar would need to be specific to the needs of these students and contain content on study skills, time management, styles of writing across disciplines, resources available on campus, and opportunities for co-curricular involvement. To create a more powerful intervention, the seminar should be taught by the students' academic advisor. The frequency of meetings and the content of the class provides an excellent opportunity for mentoring by the advisor and integration for the students.

As suggested in the literature review, some transfer students may be academically prepared for the new four-year experience, but they may not be psychologically or emotionally prepared for the challenges of the transition (Ward-Roof, Kashner, \& Hodge, 2003). Class 2 may include some students who fit this description because the students in this class performed well during the fall semester, but failed to return for the spring of the first year. It is possible these students needed additional emotional and social support to make a successful transition to the university.

The students in Class 3 may also benefit from a first-year seminar with a less intense curriculum. The students in this class appear to use the academic warning systems to identify problems and rectify GPAs before the end of the semester. Since the GPA must be below 2.0 to receive an academic deficiency at mid-semester, these students appear to let the GPAs fall below the acceptable range and then recover. This implies the students in this class are resourceful and capable, but may not have the time management skills necessary for a less chaotic record of achievement. In addition, students in Class 3 may benefit from learning communities that integrate learning across several courses and disciplines. By linking learning in the classroom to discussions in the learning community, students in Class 3 could engage in deeper learning and more meaningful educational experiences (Kuh, 2008).

Class 4 serves as a reminder that many transfer students make a smooth transition to a four-year institution and perform as well if not better academically than the first-year cohorts. The students in Class 4 are high achieving and show no indication of either academic or social struggles. Institutional support for this group of students should include high-impact practices focused on expanding the curriculum beyond the classroom. This may include undergraduate research, which has been shown to increase student and faculty interactions as well as expand students' ability to use empirical methods to grapple with the larger questions of a field (Kuh, 2008). Natural mentoring relationships form during the course of applied research, and the interactions between the student and faculty member remove the anonymity experienced by many transfer students during the first year at a four-year institution (Kuh, 2008). In addition, Class 4 contained the highest percentage of ethnic minority students. Past research has shown all students benefit from educationally purposeful activities like undergraduate research, but ethnic minority students appear to derive more benefit from these experiences when compared with ethnic majority students (Kuh, 2008). 


\section{Conclusions}

When examining a cohort of transfer students through LPA, it becomes evident that blanket interventions for all transfer students are not appropriate. The students who choose to transfer to a four-year institution differ on academic achievement and demographic variables and as such, may respond to different types of interventions. While the interventions suggested in the current study apply to the groups resulting from analysis of this particular cohort, it is possible other universities may have similar groups or could benefit from using this type of analysis.

\section{References}

Abelman, R., \& Molina, A. (2001). Style over substance revisited: A longitudinal analysis of intrusive intervention. NACADA Journal, 21(1-2), 32-39.

Adelman, C. (2005). Moving into town-and moving on: The community college in the lives of traditional-age students. Washington, DC: U.S. Department of Education.

Bai, H., \& Pan, W. (2009). A multilevel approach to assessing the interaction effects on college student retention. Journal of College Student Retention, 11(2), 287-301.

Cabrera, A. F., Burkum, K. R., \& La Nasa, S. M. (2005). Pathways to a four-year degree: Determinants of transfer and degree completion. In A. Seidman (Ed.), College student retention: Formula for student success (pp. 155-214). Westport, CT: Praeger.

Caplan, J. (2008). College orientation for the first-year and transfer student populations: How can the needs of both groups be simultaneously met during orientation and beyond? (Unpublished honors thesis). Oberlin College, Ohio.

Cejda, B. D., Kaylor, A. J., \& Rewey, K. L. (1998). Transfer shock in an academic discipline: The relationship between students' majors and their academic performance. Community College Review, 26(3), 1-13.

Collins, L. M. \& Lanza, S. T. (2010). Latent class and latent transition analysis: With applications in the social, behavioral, and health sciences. Hoboken, NJ: Wiley.

Dougherty, K. J., \& Kienzl, G. S. (2006). It's not enough to get through the open door: Inequalities by social background in transfer from community colleges to four-year colleges. Teachers College Record, 108(3), 452-487.

Elkins, S. A., Braxton, J. M., \& James, G. W. (2000). Tinto's separation stage and its influence on first-semester college student persistence. Research in Higher Education, 41, 251-268.

Glass, J. C., \& Harrington, A. R. (2002). Academic performance of community college transfer students and" native" students at a large state university. Community College Journal of Research \&Practice, 26(5), 415-430.

Gordon, V. N., \& Steele, G. E. (2003). Undecided first-year students: A 25-year longitudinal study. Journal of the First-Year Experience \& Students in Transition, 
15(1), 19-38.

Herman, J. P., \& Lewis, E. (2004). Transfer transition and orientation programs.

In T. J. Kerr, M. C. King, \& T. J. Grites (Eds.), Advising transfer students (pp. 5764). Manhattan, KS: NACADA.

Kuh, G. D. (2008). High-impact educational practices: What they are, who has access to them, and why they matter. Washington, DC: Association of American Colleges and Universities.

Laird, T. F., Shoup, R., \& Kuh, G. D. (2005). Measuring deep approaches to learning using the National Survey of Student Engagement. Paper presented at the Annual Meeting of the Association for Institutional Research. Chicago, IL.

Lee, V. E., Mackie-Lewis, C., \& Marks, H. M. (1993). Persistence to the baccalaureate degree for students who transfer from community college. American Journal of Education, 102(1), 80-114.

Melguizo, T., Kienzl, G. S., \& Alfonso, M. (2011). Comparing the educational attainment of community college transfer students and four-year college rising juniors using propensity score matching methods. Journal of Higher Education, 82(3), 265-291.

Melguizo, T., \& Dowd, A. C. (2009). Baccalaureate success of transfers and rising 4-year college juniors. Teachers College Record, 111 (1), 55-89.

Muthén, L. K., \& Muthén, B.O. (2010). Mplus user's guide (6th ed.). Los Angeles, CA: Muthén \& Muthén.

Pascarella, E. T., \& Terenzini, P. T. (1997). Studying college students in the 21st century: Meeting new challenges. The Review of Higher Education, 21(2), 151-165.

Pastor, D. A., Barron, K. E., Miller, B. J., \& Davis, S. L. (2007). A latent profile analysis of college students' achievement goal orientation. Contemporary Educational Psychology, 32(1), 8-47.

Porchea, S. F.; Allen, J.; Robbins, S.; \& Richard, P. P. (2010). Predictors of long-term enrollment and degree outcomes for community college students: Integrating academic, psychosocial, socio-demographic, and situational factors. Journal of Higher Education, 81(6), 680-708.

Rendón, L. I., Jalomo, R. E., \& Nora, A. (2000). Theoretical considerations in the study of minority student retention in higher education. In J. M. Braxton (Ed.), Reworking the departure puzzle (pp. 127-156). Nashville, TN: Vanderbilt University Press.

Thombs, D. L. (1995). Problem behavior and academic achievement among firstsemester college freshmen. Journal of College Student Development, 36(3), 280-88.

Tinto, V. (1975). Dropout from higher education: A theoretical synthesis of recent research. Review of Educational Research, 45, 89-125.

Tinto, V. (1987). Leaving college: Rethinking the causes and cures of student attrition (2nd ed.). Chicago, IL: University of Chicago Press.

Tinto, V. (1993). Building community. Liberal Education, 79(4), 16-21.

Townsend, B. K. (1995). Community college transfer students: A case study of survival. Review of Higher Education, 18(2), 175-93. 
Townsend, B. K., \& Wilson, K. (2006). "A hand hold for a little bit": Facilitating the success of community college transfer students to a large research university. Journal of College Student Development, 47, 439-456.

Townsend, B. K. (2008). "Feeling like a freshman again": The transfer student transition. New Directions for Higher Education, 2008(144), 69-77.

Ward-Roof, J. A., Kashner, P., \& Hodge, V. (2003). Orienting transfer students [Monograph]. Designing Successful Transitions: A Guide for Orienting Students to College. 2nd Edition. The First-Year Experience Monograph Series, 97-107.

Zamani, E. M. (2001). Institutional responses to barriers to the transfer process. New Directions for Community Colleges, 114, 15-24. 